\title{
Efficacy and Safety of Amphetamine Extended-Release Oral Suspension in Children with Attention-Deficit/Hyperactivity Disorder
}

\author{
Ann C. Childress, MD, Sharon B. Wigal, PhD, Matthew N. Brams, MD, John M. Turnbow, MD, \\ Yulia Pincus, PhD, Heidi W. Belden, PharmD, and Sally A. Berry, MD, PhD ${ }^{5}$
}

\begin{abstract}
Objectives: To determine the efficacy and safety of amphetamine extended-release oral suspension (AMPH EROS) in the treatment of attention-deficit/hyperactivity disorder (ADHD) in a dose-optimized, randomized, double-blind, parallel-group study. Methods: Boys and girls aged 6 to 12 years diagnosed with ADHD were enrolled. During a 5-week, open-label, doseoptimization phase, patients began treatment with 2.5 or $5 \mathrm{mg} /$ day of AMPH EROS; doses were titrated until an optimal dose (maximum $20 \mathrm{mg} /$ day) was reached. During the double-blind phase, patients were randomized to receive treatment with either their optimized dose (10-20 mg/day) of AMPH EROS or placebo for 1 week. Efficacy was assessed in a laboratory classroom setting on the final day of double-blind treatment using the Swanson, Kotkin, Agler, M-Flynn, and Pelham (SKAMP) Rating Scale and Permanent Product Measure of Performance (PERMP) test. Safety was assessed measuring adverse events (AEs) and vital signs.

Results: The study was completed by 99 patients. The primary efficacy endpoint (change from predose SKAMP-Combined score at 4 hours postdose) and secondary endpoints (change from predose SKAMP-Combined scores at 1, 2, 6, 8, 10, 12, and 13 hours postdose) were statistically significantly improved with AMPH EROS treatment versus placebo at all time points. Onset of treatment effect was present by 1 hour postdosing, the first time point measured, and duration of efficacy lasted 13 hours postdosing. PERMP data mirrored the SKAMP-Combined score data. AEs ( $>5 \%)$ reported during dose optimization were decreased appetite, insomnia, affect lability, upper abdominal pain, mood swings, and headache.

Conclusion: AMPH EROS was effective in reducing symptoms of ADHD and had a rapid onset and extended duration of effect. Reported AEs were consistent with those of other extended-release amphetamine products.
\end{abstract}

Keywords: amphetamine, attention-deficit/hyperactivity disorder, extended-release, laboratory school, oral suspension, liquid formulation

\section{Introduction}

A TTENTION-DEFICIT/HYPERACTIVITY DISORDER (ADHD) is prevalent in the United States, with a reported $11 \%$ of schoolaged children (i.e., more than 6.4 million based on 2011 estimates) affected (Visser et al. 2014). Clinical practice guidelines recommend pharmacologic treatment with psychostimulants (with or without behavioral intervention), including amphetamine, as firstline medical treatment for ADHD in patients who have no comorbid disorders (Pliszka and AACAP Work Group on Quality
Issues 2007; Subcommittee on Attention-Deficit/Hyperactivity Disorder et al. 2011). Preschool-aged children with ADHD should receive behavioral therapy alone before medication is considered (subcommittee on Attention-Deficit/Hyperactivity Disorder et al. 2011).

Extended-release (ER) formulations that obviate the need for multiple doses per day and/or dosing during school hours are generally preferred over immediate-release formulations (Pliszka and AACAP Work Group on Quality Issues 2007). Amphetamine extended-release oral suspension (AMPH EROS, Dyanavel ${ }^{\circledR} \mathrm{XR}$;

${ }^{1}$ Center for Psychiatry and Behavioral Medicine, Inc., Las Vegas, Nevada.

${ }^{2}$ AVIDA, Inc., Newport Beach, California.

${ }^{3}$ Bayou City Research, Ltd., Houston, Texas.

${ }^{4}$ Westex Clinical Investigations, Lubbock, Texas.

${ }^{5}$ Tris Pharma, Inc., Monmouth Junction, New Jersey.

Funding: The clinical trial was funded by Tris Pharma, Inc., Monmouth Junction, NJ.

(C) Ann C. Childress et al. 2018; Published by Mary Ann Liebert, Inc. This is an Open Access article distributed under the terms of the Creative Commons Attribution License, which permits unrestricted use, distribution, and reproduction in any medium, provided the original work is properly cited 
Tris Pharma, Inc., Monmouth Junction, NJ) has been approved by the U.S. Food and Drug Administration for the treatment of ADHD in children aged 6 to 17 years (Dyanavel XR 2017). The study results discussed in this article formed the basis for approval of AMPH EROS in the United States. The target product profile of the ER amphetamine liquid formulation was designed to have a rapid onset of clinical effect and duration of effect of at least 12 hours after dosing.

According to the American Academy of Pediatrics, about 50\% of pediatric patients with ADHD who fail to respond to one stimulant medication may have a positive response to another stimulant; therefore, preferential response may dictate the choice of stimulant (amphetamine or methylphenidate) for an individual patient with ADHD (American Academy of Pediatrics 2011). In addition, lowdose stimulants may produce positive, but suboptimal, effects in some children; thus, titration to maximum doses that control symptoms, while minimizing adverse effects, is preferred over titration strictly on a milligram-per-kilogram basis (subcommittee on Attention-Deficit/Hyperactivity Disorder et al. 2011). In accordance with these guidelines, the dose of AMPH EROS can be individualized based on the needs and response of the patient (Dyanavel XR 2017).

Difficulty in swallowing pills is a potential treatment barrier reported among children. In one study, 67 (54\%) of 124 children aged 6 to 11 years were initially unable to swallow a pill, and even after training, $11(16 \%)$ of the 67 children still could not swallow a pill (Meltzer et al. 2006). Furthermore, the taste and texture of the medication, especially if crushed, can influence the child's acceptance to swallow the medication (Beck et al. 2005; van Riet-Nales et al. 2016). Oral liquid formulations offer the advantage of a low dosing volume, dosing flexibility, and ease of swallowing, which is especially important in young children (van Riet-Nales et al. 2016). Thus, an ER amphetamine liquid formulation provides an ageappropriate solution for children or young adults who are unable to swallow a pill or a tablet.

Careful consideration must be exercised in selecting an optimal study design that will provide data to inform clinical decisionmaking. The laboratory classroom model provides a strictly controlled environment that enables simultaneous investigation of pharmacokinetic and pharmacodynamic parameters of response (Wigal and Wigal 2006). By age and developmentally appropriate activities, this methodology facilitates the systematic collection of information (e.g., dosing, safety, attention, behavior, and seatwork productivity) critical for the management of ADHD in clinical practice.

A long-acting liquid amphetamine may assist clinicians in individualizing the dose for each patient, while balancing effectiveness with adverse events (AEs). Therefore, an efficacy and safety study of AMPH EROS in pediatric patients with ADHD using a laboratory classroom study design (Wigal and Wigal 2006) was conducted to establish the onset and duration of clinical effect and inform clinicians making treatment decisions.

\section{Methods \\ Study design}

This was a dose-optimized, randomized, parallel-group, doubleblind, placebo-controlled laboratory classroom study conducted at five investigational centers in the United States. The study consisted of a 5-week, open-label, dose-optimization phase followed by a 1-week, randomized, double-blind, placebo-controlled phase (Fig. 1).

In the open-label phase, AMPH EROS was initiated at a starting dose of 2.5 or $5 \mathrm{mg}$, based on investigator preference, and was administered once daily in the morning. The dose was then titrated by 2.5 - to $10-\mathrm{mg}$ increments every 4 to 7 days until an optimal dose or a maximum daily dose of $20 \mathrm{mg}$ was reached. Dose titrations occurred at the investigator's discretion at each visit during the open-label phase to achieve efficacy and tolerability based on assessments of the patient's ADHD signs and symptoms using the ADHD Rating Scale, the Clinical Global Impression (CGI)Improvement scale, and the CGI-Severity scale, along with observations of potential drug-induced AEs. Dose reduction could occur at any time during the open-label phase to ensure patient safety. Patients who could not tolerate a minimum dose of $10 \mathrm{mg} /$ day were discontinued, as were patients who had not achieved a stable dose at least 1 week before entry into the double-blind phase.

At the end of 5 weeks, patients who had achieved a stable dose in the opinion of the study investigator continued to the double-blind portion of the study and were randomly assigned 1:1 to receive either AMPH EROS at their optimized dose (10-20 mg/day) or placebo orally once daily for 1 week. Efficacy was assessed in a laboratory classroom setting on the final day of the double-blind phase. Snacks and meals were provided ad libitum before dosing and during the laboratory classroom days. The fat and calorie content were not restricted.

The study was approved by the institutional review board (IRB) and was conducted in accordance with Good Clinical Practice.

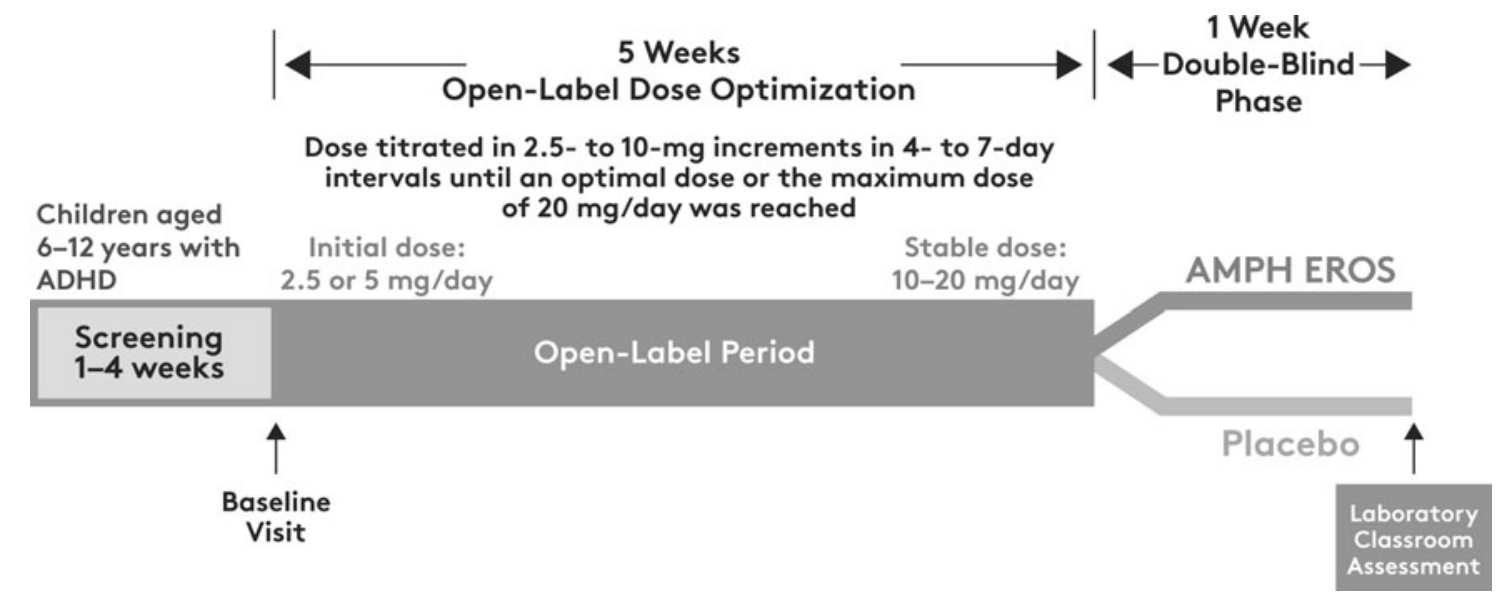

FIG. 1. AMPH EROS clinical trial design. ADHD, attention-deficit/hyperactivity disorder; AMPH EROS, amphetamine extendedrelease oral suspension. 
Table 1. AMPH EROS Clinical Trial Patient Characteristics

\begin{tabular}{|c|c|c|c|}
\hline Characteristic & $\begin{array}{l}\text { Placebo } \\
(\mathrm{n}=48)\end{array}$ & $\begin{array}{c}A M P H \text { EROS } \\
(\mathrm{n}=51)\end{array}$ & $\begin{array}{c}\text { Total } \\
(\mathrm{N}=99)\end{array}$ \\
\hline \multicolumn{4}{|l|}{ Sex, $n(\%)$} \\
\hline Male & $32(66.7)$ & $36(70.6)$ & $68(68.7)$ \\
\hline Female & $16(33.3)$ & $15(29.4)$ & $31(31.3)$ \\
\hline \multicolumn{4}{|l|}{ Age, years } \\
\hline Mean (SD) & $9.6(1.76)$ & $9.2(1.95)$ & $9.4(1.86)$ \\
\hline Median & 10.0 & 9.0 & 9.0 \\
\hline Range (min, max) & $(6,12)$ & $(6,12)$ & $(6,12)$ \\
\hline \multicolumn{4}{|l|}{ Race, $n(\%)$} \\
\hline White & $28(58.3)$ & $27(52.9)$ & $55(55.6)$ \\
\hline Black/African American & $15(31.3)$ & 19 (37.3) & $34(34.3)$ \\
\hline Other $^{\mathrm{a}}$ & $5(10.4)$ & $5(9.8)$ & $10(10.1)$ \\
\hline \multicolumn{4}{|l|}{ Ethnicity, $n(\%)$} \\
\hline Hispanic/Latino & $21(43.8)$ & $18(35.3)$ & $39(39.4)$ \\
\hline Non-Hispanic/Latino & $27(56.3)$ & $33(64.7)$ & $60(60.6)$ \\
\hline \multicolumn{4}{|l|}{ ADHD type, $n(\%)$} \\
\hline $\begin{array}{l}\text { Predominantly } \\
\text { inattentive }\end{array}$ & $8(16.7)$ & $12(23.5)$ & $20(20.2)$ \\
\hline $\begin{array}{l}\text { Predominantly } \\
\text { hyperactive/impulsive }\end{array}$ & $1(2.1)$ & 0 & $1(1.0)$ \\
\hline Combined & $39(81.3)$ & $39(76.5)$ & $78(78.8)$ \\
\hline
\end{tabular}

Intent-to-treat population.

aRace designation of "other" includes Asian, Native Hawaiian, and biracial (e.g., white and Asian, black and white, white and Native Hawaiian).

ADHD, attention-deficit/hyperactivity disorder; AMPH EROS, amphetamine extended-release oral suspension.

Investigators could not commence the study before providing evidence of IRB approval. Changes in research activity were not allowed without IRB approval, except where necessary to eliminate apparent immediate hazards to the subjects, and each investigator provided a final report to their IRB at completion of the study. Informed consent was obtained from all caregivers and/or legal representatives of the patients, or assent, as appropriate based on patient age, before the start of the study and before the conduction of any study-related procedures.

\section{Study patients}

Eligible patients were children aged 6 to 12 years, who were diagnosed with ADHD by a psychiatrist, psychologist, developmental pediatrician, pediatrician, or experienced licensed allied health professional according to the Diagnostic and Statistical Manual of Mental Disorders, Fourth Edition-Text Revision (DSM$I V-T R$ ) criteria (American Psychiatric Association 2000). ADHD was confirmed at screening using the Kiddie-Schedule for Affective Disorders and Schizophrenia (Kaufman et al. 1997) structured clinical interview. In addition, the patient must have scored $\geq 90$ th percentile for sex and age on the ADHD Rating Scale (DuPaul et al. 1998) in at least one of the following categories: hyperactiveimpulsive subscale, inattentive subscale, or total score. Finally, the investigator must have determined a need for pharmacologic treatment for ADHD.

Exclusion criteria included DSM-IV Axis I active disorder (including severe anxiety disorder, psychotic disorders, conduct disorder, pervasive developmental disorder, eating disorder, obsessivecompulsive disorder, major depressive disorder, bipolar disorder, substance use disorder, autism spectrum disorder, chronic tic disorder, or personal or family history of Tourette syndrome), clinically significant cognitive impairment, history of chronic or uncontrolled medical illness, use of prohibited drugs or monoamine oxidase inhibitors or atomoxetine within 30 days of baseline visit, and clinically significant abnormal electrocardiogram or laboratory test values at screening. A history of lack of response to amphetamine was exclusionary. Oppositional defiant disorder, specific phobias, and learning disorders were among the comorbidities permitted.

\section{Study sites}

The clinical sites selected for this study were led by Principal Investigators with recognized expertise in the conduction of laboratory classroom studies in children with ADHD. These types of studies were the basis of approval for several long-acting stimulant medications.

\section{Study assessments}

Efficacy was assessed by trained laboratory school teachers and raters using the Swanson, Kotkin, Agler, M-Flynn, and Pelham (SKAMP) Rating Scale (Wigal et al. 1998; Wigal and Wigal 2006) and the Permanent Product Measure of Performance (PERMP) test (Wigal and Wigal 2006). The SKAMP is a 13-item, teacher-rated, 7-point impairment scale that assesses manifestations of ADHD in a classroom setting and includes two derived subscales, Attention and Deportment (Wigal et al. 1998; Wigal and Wigal 2006). The PERMP is a timed, written test that measures the number of math problems attempted and solved correctly in 10 minutes (Wigal and Wigal 2006). Degree of difficulty for each child was determined by

Table 2. Patient Disposition

\begin{tabular}{lcccc}
\hline Patients & Not randomized $(\mathrm{n}=8)$ & Placebo $(\mathrm{n}=48)$ & AMPH EROS $(\mathrm{n}=52)$ & Total $(\mathrm{N}=108)$ \\
\hline Enrolled, $n(\%)$ & $8(100)$ & $48(100)$ & $52(100)$ & $108(100)$ \\
Randomized, $n(\%)$ & & $48(100)$ & $52(100)$ & $100(92.6)$ \\
Analysis populations, $n(\%)$ & $7(87.5)$ & $48(100)$ & $52(100)$ & $107(99.1)$ \\
$\quad$ Enrolled safety & & $48(100)$ & $52(100)$ & $100(92.6)$ \\
$\quad$ Randomized safety & & $48(100)$ & $51(98.1)$ & $99(91.7)$ \\
$\quad$ Intent-to-treat & $8(100)$ & $48(100)$ & $51(98.1)$ & $99(91.7)$ \\
Study completion, $n(\%)$ & & 0 & $1(1.9)$ & $9(8.3)^{\mathrm{a}}$ \\
Discontinued, $n(\%)$ & & &
\end{tabular}

Enrolled safety population.

${ }^{\text {a }}$ Reasons for discontinuation included study site terminated by sponsor due to inability to recruit a minimum cohort in the allotted time specified by the protocol $(n=4)$, consent withdrawn $(n=2)$, lost to follow-up $(n=1)$, illness on classroom day $(n=1)$, and overslept on classroom day $(n=1)$.

AMPH EROS, amphetamine extended-release oral suspension. 
Table 3. Primary Efficacy Endpoint Results (SKAMP-Combined Scores)

\begin{tabular}{|c|c|c|c|}
\hline Time point statistic & Placebo $(\mathrm{n}=48)$ & $A M P H E R O S(\mathrm{n}=51)$ & Treatment difference (AMPH EROS-placebo $)^{\mathrm{a}}$ \\
\hline \multicolumn{4}{|l|}{ Predose } \\
\hline Mean (SD) & $15.5(7.35)$ & $17.3(8.88)$ & \\
\hline Median & 14.0 & 14.0 & \\
\hline Range (min, max) & $(2,31)$ & $(5,37)$ & \\
\hline \multicolumn{4}{|l|}{4 hours postdose } \\
\hline Mean (SD) & $21.1(10.14)$ & $8.2(5.57)$ & \\
\hline Median & 19.5 & 7.0 & \\
\hline Range (min, $\max$ ) & $(6,48)$ & $(1,28)$ & \\
\hline \multicolumn{4}{|c|}{ Change at 4 hours postdose } \\
\hline Mean (SD) & $5.6(7.85)$ & $-9.1(7.51)$ & \\
\hline Median & 4.0 & -8.0 & \\
\hline Range (min, max) & $(-9,23)$ & $(-26,14)$ & \\
\hline LS mean (SE) & $6.0(1.19)$ & $-8.8(1.14)$ & $-14.8(1.61)$ \\
\hline $95 \% \mathrm{CI}$ & (3.6 to 8.3 ) & $(-11.1$ to -6.6$)$ & $(-17.9$ to -11.6$)$ \\
\hline$p$ & & & $<0.0001$ \\
\hline
\end{tabular}

Intent-to-treat population.

The SKAMP-Combined score is obtained by summing items $1-13$, where each item is rated on a 7 -point scale $(0=$ normal to $6=$ maximal impairment $)$. ${ }^{a}$ Treatment comparisons for change from predose scores were assessed using a mixed-model repeated-measures analysis, with treatment (AMPH EROS/placebo), study center, time point, and time point by treatment interaction as main effects and patient intercept as a random effect.

AMPH EROS, amphetamine extended-release oral suspension; LS, least squares; SKAMP, Swanson, Kotkin, Agler, M-Flynn, and Pelham.

an 8-minute PERMP placement test. Both SKAMP Rating Scales and PERMP tests were administered predose and at 1, 2, 4, 6, 8, 10, 12 , and 13 hours postdose in classroom sessions during the laboratory school study day.

Safety was assessed by the incidence and severity of treatmentemergent AEs (TEAEs), which were monitored and reported throughout the study. Blood pressure and pulse were measured throughout the study and potentially clinically significant measurements were tabulated. Potentially clinically significant values were defined as follows: systolic blood pressure $>95$ th percentile (observed value) or $\geq 20 \mathrm{~mm} \mathrm{Hg}$ increase from baseline, diastolic blood pressure $>95$ th percentile (observed value) or $\geq 10 \mathrm{~mm} \mathrm{Hg}$ increase from baseline, and pulse $>110 \mathrm{bpm}$ (observed value) or $\geq 25 \mathrm{bpm}$ increase from baseline. Systolic and diastolic percentiles were determined based on patients' age, gender, and height percentiles from the chart in the Fourth Report on the Diagnosis, Evaluation, and Treatment of High Blood Pressure in Children and Adolescents (National High Blood Pressure Education Program Working Group on High Blood Pressure in Children and Adolescents 2004).

Subjects' weight was measured at screening, at baseline, and at study end, 7-14 days after the last dose of double-blind study medication was administered. Suicidal thoughts and behavior were measured by trained raters at the baseline visit and at all study visits through final study visit/early termination using the ColumbiaSuicide Severity Rating Scale (C-SSRS) (Posner et al. 2011).

\section{Statistical analysis}

Efficacy analyses were based on the intent-to-treat (ITT) population, defined as randomized patients who received at least one dose of double-blind study treatment and had at least one postdose assessment of the primary efficacy variable. Safety assessments were based on the enrolled safety population, defined as enrolled patients who received at least one dose of open-label study treatment. The randomized safety population was defined as all randomized patients who received at least one dose of double-blind study treatment.
The primary efficacy endpoint was the change from predose (defined as the time immediately before AMPH EROS administration on the laboratory classroom day) in the model-adjusted average of SKAMP-Combined score at 4 hours postdose. The treatment difference between AMPH EROS and placebo was estimated using least squares (LS) means from a mixed-effects repeated-measures model with study center, treatment, time point, and time point by treatment interaction as fixed effects and patient as a random effect.

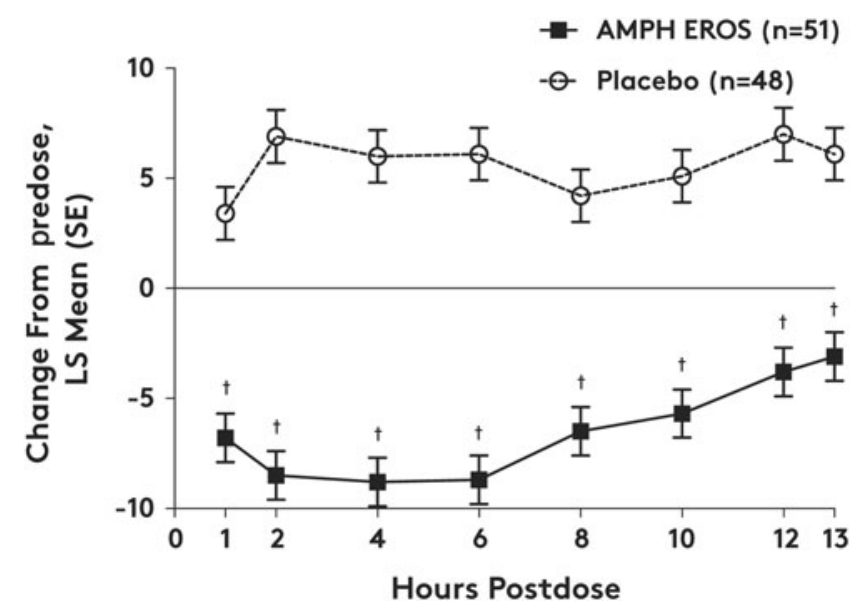

FIG. 2. Change from predose SKAMP-Combined scores over time by treatment group (ITT population). AMPH EROS, amphetamine extended-release oral suspension; ITT, intent-totreat; LS, least squares; SKAMP, Swanson, Kotkin, Agler, M-Flynn, and Pelham. The SKAMP-Combined score is obtained by summing items 1-13, where each item is rated on a 7-point scale $(0=$ normal to $6=$ maximal impairment). Treatment comparisons for change from predose scores were assessed using a mixed-model repeated-measures analysis, with treatment (AMPH EROS/placebo), study center, time point, and time point by treatment interaction as main effects and patient intercept as a random effect. ${ }^{\dagger} p<0.0001$, treatment difference relative to placebo. 

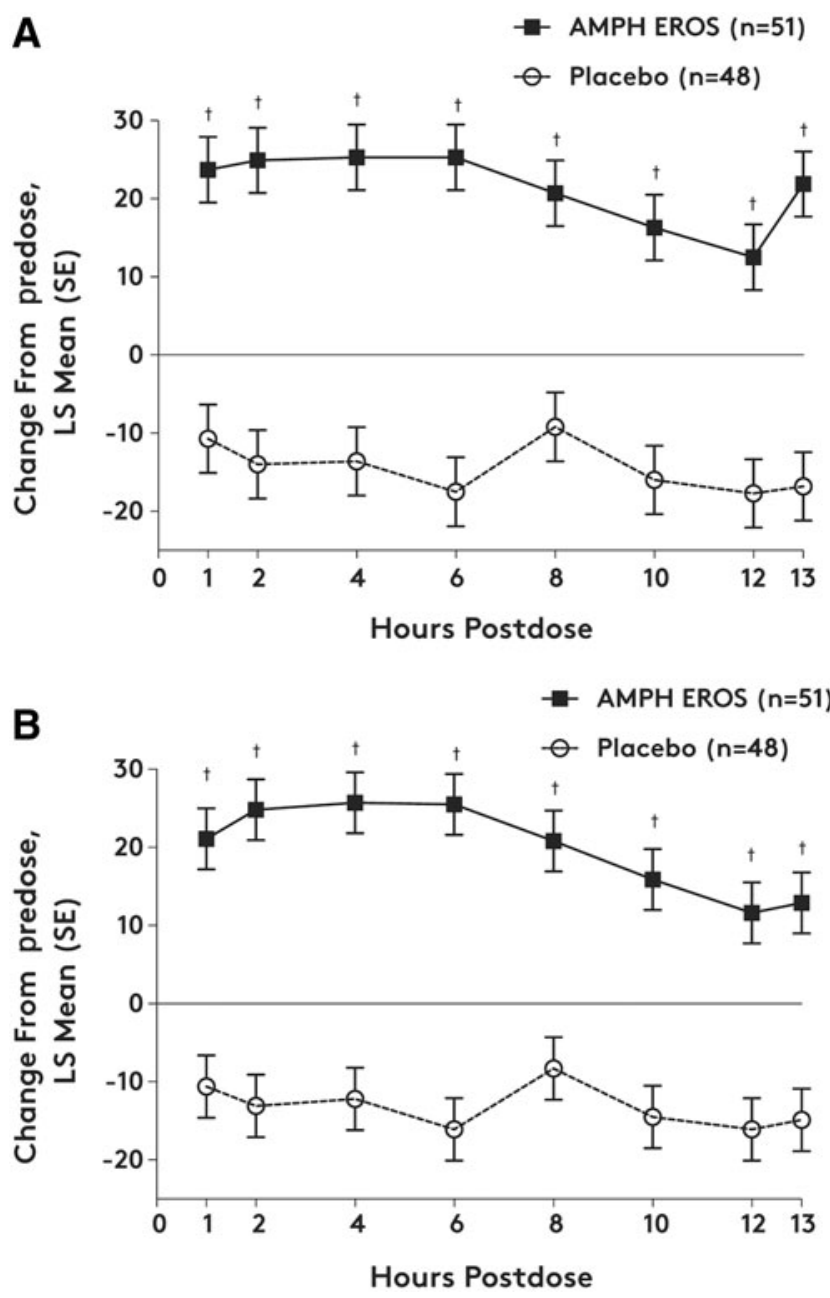

FIG. 3. Change from predose PERMP scores for (A) number of problems attempted and (B) number of problems correct over time by treatment group (ITT population). AMPH EROS, amphetamine extended-release oral suspension; ITT, intent-to-treat; LS, least squares; PERMP, Permanent Product Measure of Performance. The PERMP is a 10-minute written test with the number of problems attempted and the number of problems answered correctly used as a measure of a patient's performance. Treatment comparisons for change from predose scores were assessed using a mixed-model repeated-measures analysis, with treatment (AMPH EROS/placebo), study center, time point, and time point by treatment interaction as main effects and patient intercept as a random effect. ${ }^{\dagger} p<0.0001$, treatment difference relative to placebo.

Onset and duration of efficacy of AMPH EROS versus placebo were key secondary efficacy endpoints that used change from predose SKAMP-Combined scores and were tested with a fixed-sequence testing procedure, using the same model as the primary efficacy variable. Assessments of time difference were conducted at a time point only if all previously tested time points showed a treatment difference of $p<0.05$. Onset of efficacy occurred at the earliest postdose time point at which a statistically significant $(p<0.05)$ treatment difference was found, and duration of efficacy was the difference between onset time and the last consecutive time point at which the treatment difference was still statistically significant $(p<0.05)$.

For each treatment and for the difference between treatments, descriptive statistics were provided for SKAMP-Combined scores, SKAMP Attention scores, SKAMP Deportment scores, and
TABle 4. TEAEs Occurring In $>5 \%$ of Patients During the Open-Label Phase and All TEAEs REPORTED IN THE AMPH EROS GROUP During the Double-Blind Phase

\begin{tabular}{lccc}
\hline & $\begin{array}{c}\text { Open-label } \\
\text { phase } \\
\text { AMPH EROS } \\
(\mathrm{n}=107)\end{array}$ & $\begin{array}{c}\text { Double-blind } \\
\text { study phase }\end{array}$ \\
\cline { 3 - 4 } TEAE & $28(26.2)$ & 0 & $1(1.9)$ \\
$(\mathrm{n}=48)$ & $\begin{array}{c}\text { AMPH EROS } \\
(\mathrm{n}=51)\end{array}$ \\
\hline Decreased appetite & $14(13.1)$ & $1(2.1)$ & $1(1.9)$ \\
Insomnia & $10(9.3)$ & 0 & 0 \\
Affect lability & $8(7.5)$ & $1(2.1)$ & $2(3.8)$ \\
Upper abdominal pain & $6(5.6)$ & 0 & 0 \\
Mood swings & $6(5.6)$ & $1(2.1)$ & $1(1.9)$ \\
Headache & $1(0.9)$ & 0 & $2(3.8)$ \\
Epistaxis & 0 & 0 & $2(3.8)$ \\
Allergic rhinitis & 0 & 0 & $1(1.9)$ \\
Musculoskeletal pain & $4(3.7)$ & $1(2.1)$ & $1(1.9)$ \\
Vomiting & $2(1.9)$ & $1(2.1)$ & $1(1.9)$ \\
Viral gastroenteritis & & & \\
\hline
\end{tabular}

All values are $n(\%)$.

AMPH EROS, amphetamine extended-release oral suspension; TEAE, treatment-emergent adverse event.

PERMP scores at each time point during the laboratory classroom session; variables were also analyzed using a mixed-model repeated-measures method.

\section{Results}

Demographic and baseline clinical characteristics are shown in Table 1 . More boys $(68.7 \%)$ than girls $(31.3 \%)$ participated in the study. The study population was $55.6 \%$ white, $34.3 \%$ black, $1 \%$ Asian, 2\% Native Hawaiian or other Pacific Islander, and 7\% biracial; $39.4 \%$ were of Hispanic/Latino ethnicity. Most patients had inattentive $(20.2 \%)$ or combined type $(78.8 \%)$ ADHD. Five subjects $(4.7 \%)$ had comorbid oppositional defiant disorder and two participants (1.9\%) had specific phobias.

\section{Patient disposition}

Study enrollment included 108 patients, with 107 included in the enrolled safety population and 100 of these in the randomized safety population. A total of 99 patients (AMPH EROS, $n=51$; placebo, $n=48$ ) completed the study and were included in the ITT population (Table 2). Nine patients discontinued from the study, eight during the open-label phase and one after randomization to AMPH EROS. In the open-label phase, the primary reason $(4 / 8$ patients; $50.0 \%$ ) for study discontinuation was termination of a study site by the sponsor due to lack of subject enrollment; after randomization, one patient discontinued because of an illness on a laboratory school study day (Table 2).

\section{Efficacy assessments}

The primary efficacy endpoint of change from predose in the model-adjusted average of SKAMP-Combined score observed at 4 hours postdose was met (LS mean treatment difference [95\% CI], -14.8 [-17.9 to -11.6$], p<0.0001$; Table 3). Each site demonstrated a statistically significant treatment effect in the primary efficacy analysis. For the key secondary endpoints, the onset of treatment effect occurred at the earliest time point assessed, 1 hour postdose (treatment difference LS mean [SE], -10.2 [1.61], 
Table 5. Potentially Clinically Significant Vital Sign Values During the Double-Blind Phase

\begin{tabular}{|c|c|c|c|c|}
\hline Parameter & Criteria & Placebo $(\mathrm{n}=48)$ & $A M P H E R O S(\mathrm{n}=52)$ & Total $(\mathrm{N}=100)$ \\
\hline Systolic blood pressure & $\begin{array}{l}\text { Postbaseline value }>95 \text { th percentile } \\
\text { Increase from baseline } \geq 20 \mathrm{~mm} \mathrm{Hg}\end{array}$ & $\begin{array}{l}2(4.2) \\
1(2.1)\end{array}$ & $\begin{array}{c}2(3.8) \\
0\end{array}$ & $\begin{array}{l}4(4.0) \\
1(1.0)\end{array}$ \\
\hline Diastolic blood pressure & $\begin{array}{l}\text { Postbaseline value }>95 \text { th percentile }{ }^{\mathrm{a}} \\
\text { Increase from baseline } \geq 10 \mathrm{~mm} \mathrm{Hg}\end{array}$ & $\begin{array}{c}0 \\
6(12.5)\end{array}$ & $\begin{array}{l}1(1.9) \\
6(11.5)\end{array}$ & $\begin{aligned} 1 & (1.0) \\
12 & (12.0)\end{aligned}$ \\
\hline Pulse & $\begin{array}{l}\text { Postbaseline value }>110 \mathrm{bpm} \\
\text { Increase from baseline } \geq 25 \mathrm{bpm}\end{array}$ & $\begin{array}{l}0 \\
0\end{array}$ & $\begin{array}{l}0 \\
0\end{array}$ & $\begin{array}{l}0 \\
0\end{array}$ \\
\hline
\end{tabular}

Randomized safety population; all values are $n(\%)$.

${ }^{a}$ The 95th percentile for the systolic and diastolic blood pressure measurements was calculated based on each patient's age, gender, and height percentile.

AMPH EROS, amphetamine extended-release oral suspension.

$p<0.0001)$. The duration of efficacy persisted until the final time point at 13 hours postdose (treatment difference LS mean [SE], -9.2 [1.61], $p<0.0001)$. At each postdose time point measured throughout the laboratory classroom day, the change from predose SKAMP-Combined score was statistically significantly improved following treatment with AMPH EROS versus placebo (Fig. 2).

The SKAMP Attention and Deportment subscale scores demonstrated significant response to AMPH EROS at all postdose time points (at least $p<0.05$ ). The treatment difference (LS mean [SE]) for the average change across all time points between AMPH EROS and placebo was -2.2 (0.39) for Attention and -3.3 (0.51) for Deportment ( $p<0.0001$ for both), with effect sizes of 1.1 and 1.3 for Attention and Deportment, respectively. PERMP scores (problems attempted and problems correct) were significantly improved with AMPH EROS at all postdose time points compared with placebo $(p<0.0001)$. The treatment difference (LS mean [SE]) for the average change across all time points between AMPH EROS and placebo was 35.7 (4.59) for attempted problems and 33.0 (4.38) for correct problems ( $p<0.0001$ for both; Fig. 3).

\section{Safety assessments}

The mean (SD) length of exposure to study medication was 36.6 (6.72) days, and the mean (SD) final optimized daily dose was 15.4 (4.10) $\mathrm{mg}$ or $0.47(0.16) \mathrm{mg} / \mathrm{kg}$.

During the open-label phase, 64 patients $(59.8 \%)$ reported $\geq 1$ TEAE. The dose of AMPH EROS was reduced in five patients, each with a report of a moderate TEAE (insomnia [ $n=3]$, dysphoria $[n=1]$, and fingernail picking $[n=1]$ ) during weeks 2 to 3 ; all resolved except for the fingernail picking. A total of 26 subjects experienced a moderate TEAE during the open-label phase. During the double-blind phase, 15 patients (AMPH EROS, $n=9$ [17.3\%]; placebo, $n=6[12.5 \%]$ ) reported $\geq 1$ TEAE (Table 4). During the open-label phase of the study, $26 \%$ reported a decreased appetite, while $1 \%$ reported a decreased appetite during the double-blind phase of the study. An AE of weight decreased was reported for three subjects in this study. Two of those AEs were rated as mild in severity and were associated with a pound and 2-pound weight loss, respectively. The third report of weight decreased was rated as moderate in severity and was associated with an 8-pound weight loss.

Potentially clinically significant vital sign values during the double-blind phase are shown in Table 5. There were no deaths or serious TEAEs reported during the study, and there were no TEAEs leading to premature withdrawal of study medication. Most $(78.0 \%)$ TEAEs were reported as mild in severity, and none was severe. No patient reported suicidal ideation or behavior on the CSSRS during any phase of the study.

\section{Discussion}

In this study, treatment with AMPH EROS resulted in a statistically significant $(p<0.0001)$ improvement in the change from predose SKAMP-Combined score at 4 hours postdose compared with placebo in children with ADHD. Consistent with the findings for the SKAMP-Combined scores, SKAMP Attention and Deportment subscales and PERMP scores showed significant improvement with AMPH EROS versus placebo at all assessed time points, which indicates that AMPH EROS is effective in treating both domains of ADHD—attention and hyperactivity/impulsivity. The results of this study establish the efficacy and safety of this new ER liquid formulation of amphetamine.

A significant separation from placebo occurred at each postdose time point assessed $(1,2,4,6,8,10,12$, and 13 hours), with onset of action of AMPH EROS at 1 hour postdose and duration of efficacy extending to 13 hours postdose $(p<0.0001)$. Although no pharmacokinetic/pharmacodynamic relationship has been established for AMPH EROS, the plasma concentration over time curve in children 6-12 years of age is characterized by a rapid initial absorption with levels peaking around 4-5 hours postdosing and then slowly declining over the remainder of the day (Dyanavel XR 2017). Clinical effect in our study population is expected within an hour of dosing and, when dosed optimally, the effect should last for 13 hours postdose.

A robust treatment effect was observed with AMPH EROS in this study, with effect sizes of 1.8 for the SKAMP-Combined score and 1.1 and 1.3 for the SKAMP Attention and Deportment subscales, respectively. In a meta-analysis conducted by Faraone et al. (2009), the effect size among six long-acting stimulants was 0.95 , with the highest effect sizes reported for dextroamphetamine (1.13) and lisdexamfetamine dimesylate (1.52). Thus, the effect sizes found for AMPH EROS are consistent with other long-acting stimulants.

AMPH EROS was well tolerated; most reported TEAEs were mild in severity, and no severe events were reported. As might be expected, TEAEs attenuated over time; thus, more patients reported $\geq 1$ TEAE during the open-label phase $(60 \%)$ than during the double-blind phase (15\%). During the open-label phase, decreased appetite (26.2\%), insomnia (13.1\%), and affect lability (9.3\%) were most commonly reported with AMPH EROS. Overall, the safety profile of AMPH EROS is similar to that for other long-acting amphetamines (Biederman et al. 2002; McCracken et al. 2003; Wigal et al. 2009). There were no deaths, serious AEs, or reports of suicidal ideation or behavior during the study.

Long-acting medications for the treatment of ADHD have slower rises and lower peak levels of stimulant blood levels, 
which may lessen the likelihood of abuse and dependence (Cascade et al. 2008). Nonetheless, patients should be assessed for the risk of abuse before the drug is prescribed and monitored for signs of abuse and dependence while on therapy. In addition, there may be an increased potential for diversion of controlled substances arising from family members or friends of family members (Upadhyaya 2008).

There are a number of strengths of this study. First, the laboratory school protocol design used in this study allowed for a precise determination of drug onset and duration of clinical effect. The 5-week dose optimization period allowed each patient to be titrated to a stable dose, with investigators' clinical judgment and assessment of tolerability and efficacy reflecting how dose optimization decision-making occurs in clinical practice.

The selected primary outcome variable gives credence to the importance of both domains of ADHD (i.e., attention and hyperactivity/impulsivity), with the subscales allowing assessment of the drug's effect on each individual domain. The PERMP results mirrored the SKAMP results, thereby helping to validate the primary outcome finding. Use of a parallel-group study design limited the exposure to placebo to 1 week. Finally, the demographics of the study population in this study reflect a typical clinic population with respect to frequency of ADHD types, gender, and race, although it included a strong representation of Hispanic ethnicity.

Some potential limitations of this study included the short study duration, which precludes any conclusions regarding the long-term use of AMPH EROS in the studied population. Study patients were dosed more aggressively (i.e., required to reach a minimum dose of $10 \mathrm{mg} /$ day) and were managed by experts in the field, which may not be typical in clinical practice. Thus, findings from this study may not generalize to children with ADHD cared for in primary care clinics where lower doses of stimulants may be used (Jensen et al. 2001). In addition, patients with significant psychiatric comorbidities were excluded, which may limit the generalizability of these data. Finally, the study was not powered to determine differential responses to treatment, if any, per ethnicity, race, or ADHD subtype.

\section{Conclusions}

The efficacy of AMPH EROS, the first ER liquid amphetamine formulation, versus placebo was demonstrated and showed a rapid onset of action and extended duration of clinical effect in children aged 6 to 12 years with ADHD. AMPH EROS was well tolerated in this study, with a safety profile similar to that of other long-acting amphetamines.

\section{Clinical Significance}

The results of this study establish, in an analog classroom setting, that AMPH EROS, a new ER liquid formulation of amphetamine, was safe and effective in the treatment of children aged 6 to 12 years with ADHD. The study design, similar to laboratory analog classroom studies with other agents used for ADHD, demonstrated a statistically significant improvement in deportment and attention (as assessed by trained, blinded raters) from 1 to 13 hours after a morning dose of AMPH-EROS. AEs, as with other agents, tended to be mild to moderate in severity and did not result in study discontinuation in any of the patients. As with all such study designs measuring short-term treatment effects, the question of longterm outcome in later childhood and in adulthood is left to future studies to address.

\section{Acknowledgments}

J.M.T. and Westex Clinical Investigations acknowledge the invaluable assistance of Sean T. Turnbow, Jessica M. Phillips, Masako H. Turnbow, and Marilyn A. Turnbow in the successful completion of this trial. S.B.W. and AVIDA, Inc. acknowledge the invaluable assistance of Audrey Kapelinski and Erin O'Carroll-Godinez.

\section{Disclosures}

A.C.C. has served as a consultant for Arbor, Ironshore Pharmaceuticals \& Development, Inc., Neos, Neurovance, Rhodes, Sunovion, and Shire; has received research support from Alcobra, Arbor, Forest Research Institute, Ironshore Pharmaceuticals \& Development, Inc., Lilly USA, LLC, Lundbeck, Medgenics, Neos, Neurovance, Noven, Otsuka, Pfizer, Inc., Purdue, Rhodes, Shire, Sunovion, and Tris Pharma, Inc.; has served as a speaker for Arbor, Pfizer, Inc., Shire, and Tris Pharma, Inc.; has served as an advisory board member for Arbor, Ironshore Pharmaceuticals \& Development, Inc., Neos, Neurovance, NLS-1, Noven, Pfizer, Inc., Rhodes, and Tris Pharma, Inc.; and has provided writing support for Arbor, Ironshore Pharmaceuticals \& Development, Inc., Neos, Pfizer, Inc., Rhodes, and Shire. S.B.W. has served as a consultant for Atentiv, Eli Lilly, Inc., Ironshore Pharmaceuticals \& Development, Inc., Neurovance, NLS, NuTec, Pfizer, Inc., Purdue, Rho, Rhodes, Shire, Sunovion, and Tris Pharma, Inc.; has received research support from Akili, Eli Lilly, Inc., Ironshore Pharmaceuticals \& Development, Inc., Neurovance, NLS, NuTec, Pfizer, Inc., Purdue, Rho, Rhodes, Shionogi Pharmaceuticals, Shire, Sunovion, and Tris Pharma, Inc.; and has served as a speaker/advisory board member for Eli Lilly, Inc., Ironshore Pharmaceuticals \& Development, Inc., NuTec, Pfizer, Purdue, Rho, Rhodes, and Shionogi Pharmaceuticals. M.N.B. has served as a speaker for Neos, Lundbeck, Otsuka, Sunovion, Takeda, and Tris Pharma, Inc., and has served as an advisory board member for Neos, Shire, and Tris Pharma, Inc. J.M.T. has received research support from Eli Lilly, Inc., Ironshore Pharmaceuticals \& Development, Inc., Pfizer, Inc., Shionogi Pharmaceuticals, Shire US, and Tris Pharma, Inc., and has served as a consultant for Celltech US, Shionogi Pharmaceuticals and Shire US. Y.P., H.W.B., and S.A.B. are employees of Tris Pharma, Inc., Monmouth Junction, NJ. H.W.B., and S.A.B. were employees of Pfizer, Inc., before their current employment at Tris Pharma, Inc. The sponsor of the study participated in study design, data collection, data analysis, data interpretation, review and approval of the final report, and provision of the study drug. All authors had full access to the data in the study and all had final responsibility for the decision to submit the report for publication. Editorial support for development of this article was provided by Maryann T. Travaglini, PharmD, Complete Healthcare Communications, LLC (West Chester, PA, USA), and funded by Tris Pharma, Inc.

\section{References}

American Academy of Pediatrics: Supplemental information. Implementing the key action statements: an algorightm and explanation for process of care for the evaluation, diagnosis, treatment, and monitoring of ADHD in children and adolescents. 2011. Available at: http://pediatrics.aappublications.org/content/suppl/2011/10/11/ peds.2011-2654.DC1/zpe611117822p.pdf Accessed May 31, 2017. American Psychiatric Association: Diagnostic and Statistical Manual of Mental Disorders, 4th ed. Washington, DC: American Psychiatric Association; 1994. 
Beck MH, Cataldo M, Slifer KJ, Pulbrook V, Guhman JK: Teaching children with attention deficit hyperactivity disorder (ADHD) and autistic disorder (AD) how to swallow pills. Clin Pediatr (Phila) 44: 515-526, 2005.

Biederman J, Lopez FA, Boellner SW, Chandler MC: A randomized, double-blind, placebo-controlled, parallel-group study of SLI381 (Adderall XR) in children with attention-deficit/hyperactivity disorder. Pediatrics 110:258-266, 2002.

Cascade E, Kalali AH, Weisler RH: Short-acting versus long-acting medications for the treatment of ADHD. Psychiatry (Edgmont) 5: 24-27, 2008.

American Psychiatric Association: Diagnostic and Statistical Manual of Mental Disorders-Text Revision: DSM-IV-TR, 4th ed. Washington, DC: American Psychiatric Association; 2000. xxxvii, $943 \mathrm{p}$.

DuPaul GJ, Power TJ, Anastopoulos AD, Reid R: ADHD Rating Scale-IV: Checklists, Norms, and Clinical Interpretation. New York, NY: The Guilford Press, 1998.

Dyanavel XR (amphetamine extended-release oral suspension): Full Prescribing Information. Monmouth Junction, NJ: Tris Pharma, Inc., 2017.

Faraone SV: Using meta-analysis to compare the efficacy of medications for attention-deficit/hyperactivity disorder in youths. P T 34:678-694, 2009.

Jensen P, Hinshaw SP, Swanson JM, Greenhill LL, Conners CK, Arnold LE, Abikoff HB, Elliott G, Hechtman L, Hoza B, March JS, Newcorn JH, Severe JB, Vitiello B, Wells K, Wigal T: Findings from the NIMH multimodal treatment study of ADHD (MTA): Implications and applications for primary care providers. J Dev Behav Pediatr 22:60-73, 2001.

Kaufman J, Birmaher B, Brent D, Rao U, Flynn C, Moreci P, Williamson D, Ryan N: Schedule for Affective Disorders and Schizophrenia for School-Age Children-Present and Lifetime Version (K-SADS-PL): Initial reliability and validity data. J Am Acad Child Adolesc Psychiatry 36:980-988, 1997.

McCracken JT, Biederman J, Greenhill LL, Swanson JM, McGough JJ, Spencer TJ, Posner K, Wigal S, Pataki C, Zhang Y, Tulloch S: Analog classroom assessment of a once-daily mixed amphetamine formulation, SLI381 (Adderall XR), in children with ADHD. J Am Acad Child Adolesc Psychiatry 42:673-683, 2003.

Meltzer EO, Welch MJ, Ostrom NK: Pill swallowing ability and training in children 6 to 11 years of age. Clin Pediatr (Phila) 45: 725-733, 2006.

National High Blood Pressure Education Program Working Group on High Blood Pressure in Children and Adolescents: The fourth report on the diagnosis, evaluation, and treatment of high blood pressure in children and adolescents. Pediatrics 114:555-576, 2004.
Pliszka S; AACAP Work Group on Quality Issues: Practice parameter for the assessment and treatment of children and adolescents with attention-deficit/hyperactivity disorder. J Am Acad Child Adolesc Psychiatry 46:894-921, 2007.

Posner K, Brown GK, Stanley B, Brent DA, Yershova KV, Oquendo MA, Currier GW, Melvin GA, Greenhill L, Shen S, Mann JJ: The Columbia-Suicide Severity Rating Scale: Initial validity and internal consistency findings from three multisite studies with adolescents and adults. Am J Psychiatry 168:1266-1277, 2011.

Subcommittee on Attention-Deficit/Hyperactivity Disorder, Steering Committee on Quality Improvement and Management, Wolraich M, Brown L, Brown RT, DuPaul G, Earls M, Feldman HM, Ganiats TG, Kaplanek B, Meyer B, Perrin J, Pierce K, Reiff M, Stein MT, Visser S: ADHD: Clinical practice guideline for the diagnosis, evaluation, and treatment of attention-deficit/hyperactivity disorder in children and adolescents. Pediatrics 128:1007-1022, 2011.

Upadhyaya HP: Substance use disorders in children and adolescents with attention-deficit/hyperactivity disorder: Implications for treatment and the role of the primary care physician. Prim Care Companion J Clin Psychiatry 10:211-221, 2008.

van Riet-Nales DA, Schobben AF, Vromans H, Egberts TC, Rademaker CM: Safe and effective pharmacotherapy in infants and preschool children: importance of formulation aspects. Arch Dis Child 101:662-669, 2016.

Visser SN, Danielson ML, Bitsko RH, Holbrook JR, Kogan MD, Ghandour RM, Perou R, Blumberg SJ: Trends in the parent-report of health care provider-diagnosed and medicated attention-deficit/ hyperactivity disorder: United States, 2003-2011. J Am Acad Child Adolesc Psychiatry 53:34-46 e32, 2014.

Wigal SB, Gupta S, Guinta D, Swanson JM: Reliability and validity of the SKAMP rating scale in a laboratory school setting. Psychopharmacol Bull 34:47-53, 1998.

Wigal SB, Kollins SH, Childress AC, Squires L: A 13-hour laboratory school study of lisdexamfetamine dimesylate in school-aged children with attention-deficit/hyperactivity disorder. Child Adolesc Psychiatry Ment Health 3:17, 2009.

Wigal SB, Wigal TL: The laboratory school protocol: Its origin, use, and new applications. J Atten Disord 10:92-111, 2006.

Address correspondence to:

Ann C. Childress, MD

Center for Psychiatry and Behavioral Medicine, Inc. 7351 Prairie Falcon Road, Suite 160 Las Vegas, NV 89128

E-mail: drann87@aol.com 